\title{
Foreword to the Thematic Section - Methods of Comparative Education
}

\section{Lesley Bartlett' Nora Krawczyk"}

'University of Wisconsin-Madison, Madison - United States of America "Universidade Estadual de Campinas (UNICAMP), Campinas/SP - Brazil

The field of Comparative and International Education is premised upon the notion of comparison. However, there is little to no agreement upon what constitutes comparative methods. This absence is perhaps unsurprising, given that the field is utterly multidisciplinary. Comparison means different things to different scholars, who are informed by different epistemologies and methods. There are two general approaches to comparison: those that are variance-oriented (and therefore tend to rely on a positivist epistemology and use quantitative methods), and those that are process-oriented (and thus tend to employ a more interpretive, constructivist, or critical epistemology and qualitative methods).

In the multidisciplinary field of comparative education, comparison has come to mean different things to different people. For many years, there was an underlying assumption that comparison must be cross-national. This trend dates from the 1960s and 1970s, when scholars like Harold Noah and Max Eckstein sought to move the field away from more historically-informed methods and toward a hypothesisdriven social science, as reflected in their book Toward a Science of Comparative Education (1969). This tendency persists today in the field of comparative education, if perhaps unconsciously (Phillips; Schweisfurth, 2014). For example, in her review of comparative education publications, Little (2000, p. 285) pointed out that few articles engage "an explicitly comparative approach" because "the majority of articles focus on single countries". The assumption is that comparison is, by definition, cross-national (or cross-cultural, with culture being used in an erroneous fashion to designate time- and place-bound groups, like a nation-state) (see Bartlett; Vavrus, 2017).

However, contemporary comparative education scholars have vigorously defended the value of other types of comparison. Steiner-

Educação \& Realidade, Porto Alegre, v. 42, n. 3, p. 815-819, July/Sept. 2017. 815 http://dx.doi.org/10.1590/2175-623674186 
Foreword to the Thematic Section - Methods of Comparative Education

Khamsi (2010, p. 327) warned educational policy scholars to avoid methodological nationalism, which is "[...] the trap of first establishing national boundaries, only to demonstrate afterward that these boundaries have indeed been transcended. [Policy] reforms do not have a home base, a territory, or a nationality and therefore do not 'belong' to a particular educational system”. Phillips and Schweisfurth (2014, p. 115) also insisted that the state is not sufficiently coherent to serve as an exemplary unit of comparison. They contended that "[...] comparativists should seek out units of analysis that are intrinsically appropriate to the task at hand".

Major scholars in the field have used critical or constructivist epistemological approaches and qualitative methods. For example, Tobin and colleagues used video-cued ethnographic techniques to compare preschool education within the US, Japan, and China. In the original study, Tobin et al. (1989) video-taped, in one early childhood location per country, a set of "critical incidents," such as classroom routines, separation, misbehavior, and mixed-aged play. They then presented the video to the educators themselves, to fellow educators in the same location, and to educators of other nationalities in the peer locations; they used the videos as cues to prompt the actors to make sense of and compare actions. In their innovative restudy in the same three countries, Tobin et al. (2009) built in two further explicit comparisons. First, based on educator nominations, the researchers selected an additional innovative school in each country, prompting comparison with the original school. Second, the researchers returned to the original schools, shooting new videotape of the same category of incidents, thus allowing comparison across time (2009). These studies provide one methodologically innovative avenue for comparison. Others have used qualitative methods to develop key conceptual contributions. For example, Carney (2009) creatively compared the educational policyscape of three countries (Denmark, Nepal, and China) in three different domains (higher education, general education, non-university-based teacher education). Carney (2009, p. 68) demonstrated how a policyscape (defined as an "[...] educational ideoscape [...] that might capture some essential elements of globalization as a phenomenon (object and process) and provide a tool with which to explore the spread of policy ideas and pedagogical practice across different national school systems") binds dissimilar countries together as they reform their education systems in ways that evidence strikingly similar "visions, values, and ideology" (Carney, 2009, p. 79). Finally, many contemporary CIE scholars make extensive use of intranational comparison. For example, in her study of human rights education (HRE) in India, Monisha Bajaj (2012) integrated several comparative angles. Bajaj focused on a very influential national NGO, the Institute of Human Rights Education (part of the larger human rights NGO People's Watch), which was active in 18 states across India. Engaging a historical perspective, her study presented the key events that led to the growth and expansion of the Institute's programs. Next, Bajaj mapped Human Rights Education across on six

816 Educação \& Realidade, Porto Alegre, v. 42, n. 3, p. 815-819, July/Sept. 2017. 
states, conducting surveys in hundreds of schools. Bajaj also conducted focus groups, interviews, and observations at more than 60 schools and with nine different NGOs (most affiliated with the Institute of Human Rights Education). She was particularly attentive to how teachers and students interpreted and took up HRE. Thus, despite the dominant notion of cross-national comparison using quantiative methods, scholars in the field use "comparison" in a variety of ways.

We posit that scholars could benefit from critically considering the range of meanings attached to comparative methods. In this issue of the journal Educação \& Realidade, scholars from a range of disciplines offer epistemological and methodological insights regarding how comparison might best be leveraged in the field.

In their article, Comparative Studies: historical, epistemological and methodological notes, Piovani and Krawczyk address historical, epistemological and methodological issues related to comparative studies in the social sciences of education. They begin by interrogating the various meanings of comparison, from scientific method to sociohistorical comparisons. They conclude by recommending a flexible, trans-contextual focus (cross-national and cross-cultural), allied with various research methods.

Informed by his perspective as a political economist using quantitative methods, Klees, in Quantitative Methods in Comparative Education and Other Disciplines: are they valid?, raises fundamental questions about the utility of regression analysis for causal inference. He argues that the conditions necessary for regression analysis to yield valid causal inferences are rarely if ever met. Instead, he encourages scholars to consider alternative research methodologies.

In their article, Comparing Policies in a Globalizing World: methodological reflections, Robertson and Dale consider the implications of globalization and shifting modes of educational policy governance for comparative methods. They identify the benefits and constraints of two conflicting ways in which comparison could be engaged to study educational policy. In summary, they offer several methodological reflections regarding lenses to engage, including time, space, and logics of governing.

From a distinct but compatible perspective, Gorostiaga, in Perspectivism and Social Cartography: contributions to comparative education, engages social cartography to develop a perspectivist approach that provides a form of comparison (defined here as the analysis of similarities, differences and inter-relationships between different perspectives). Drawing on an analysis of Latin American educational reform debates from 1996-2008, Gorostiaga outlines the methodological features of social cartography and its potential contributions to the field of comparative education.

The article by Bartlett and Vavrus, Comparative Case Studies, focuses specifically on case study methods and their potential for comparison. Based on a review and critique of dominant approaches to case 
Foreword to the Thematic Section - Methods of Comparative Education

study research in the field of education, the authors ipropose a new approach - the comparative case study approach - that engages three "axes" of comparison, including vertical, horizontal, and transversal (see also Bartlett; Vavrus 2017; 2014a; 2014b; Vavrus; Bartlett, 2009 for examples). In developing this approach, they propose a reconceptualization of comparison and predominant understandings of context.

Based on contributions from Friedrich Tenbruck and Joachim Matthes, Weller offers a critical cultural analysis of comparative methods, in Understanding the Operation Called Comparison. He presents two international research studies with an emphasis on the methodological procedures, offering a reflection on the value of different approaches to comparison in these projects, including revealing surprising and unanticipated outcomes.

In their chapter, Interculturality and Education in Argentina from a Comparative Perspective, Novaro, Padawer, and Borton compare two ethnographic studies - one conducted in mbyá guarani villages from Northwestern Argentina, and the other done in a suburban site in Buenos Aires city, mostly populated by Bolivian migrants. The authors compare the similar processes both minoritized populations undergo, including displacement, poverty, and a struggle to maintain ethnic identities in the face of heavy pressure to assimilate. In this way, the authors exemplify the unexpected value in post-hoc comparison of ethnographic studies.

\section{References}

BAJAJ, Monisha. Schooling for Social Change: the rise and impact of human rights education in India. New York: Bloomsbury Academic, 2012.

BARTLETT, Lesley; VAVRUS, Frances. Transversing the vertical case study: a methodological approach to studies of educational policy as practice. Anthropology \& Education Quarterly, New Jersey, v. 45, n. 2, p. 131-147, 2014a.

BARTLETT, Lesley; VAVRUS, Frances. Studying globalization. In: STROMQUIST, Nelly; MONKMAN, Karen G. (Ed.). Globalization and Education: integration and contestation across cultures. Lanham, MD: Rowman and Littlefield, 2014b. P. 119-131.

BARTLETT, Lesley; VAVRUS, Frances. Rethinking Case Study Research: the comparative case study approach. New York: Routledge, 2017.

CARNEY, Stephen. Negotiating policy in an age of globalization: exploring educational "policyscapes" in Denmark, Nepal, and China. Comparative Education Review, Chicago, v. 53, n. 1, p. 63-88, 2009.

LITTLE, Angela. Development studies and comparative education: context, content, comparison and contributors. Comparative Education, v. 36, n. 3, p. 279-296, 2000.

PHILLIPS, David; SCHWEISFURTH, Michele. Comparative and International Education: an introduction to theory, method, and practice. New York: Bloomsbury, 2014.

STEINER-KHAMSI, Gita. The politics and economics of comparison. Comparative Education Review, Chicago, v. 54, n. 3, p. 323-342, 2010.

818 Educação \& Realidade, Porto Alegre, v. 42, n. 3, p. 815-819, July/Sept. 2017. 
TOBIN, Joseph; WU, David Y. H.; DAVIDSON, Dana H. Preschool in Three Cultures: Japan, China, and the United States. New Haven, CT: Yale University Press, 1989

TOBIN, Joseph; HSUEH, Yeh; KARASAWA, Mayumi. Preschool in Three Cultures Revisited: China, Japan, and the United States. Chicago: University of Chicago Press, 2009.

VAVRUS, Frances; BARTLETT, Lesley (Ed.). Critical Approaches to Comparative Education: vertical case studies from Africa, Europe, the Middle East, and the Americas. New York: Palgrave Macmillan, 2009.

Lesley Bartlett is a Professor in Educational Policy Studies and a faculty affiliate in Anthropology. An anthropologist by training who works in the field of International and Comparative Education, Professor Bartlett does research in literacy studies (including multilingual literacies), migration, and educator professional development.

E-mail: lesley.bartlett@wisc.edu

Nora Krawczyk is Magister in Education and Society from the Latin American Faculty of Social Sciences - FLACSO/Argentina and a Doctorate in Education from the State University of Campinas - Unicamp/Brazil. She is currently a professor and researcher in the Department of Social Sciences and Education of the School of Education/University of Campinas - UNICAMP and researcher of the National Research Council - CNPq. She has experience in the area of politics and sociology of Education in Brazil and in Latin America.

E-mail: 3105nora@gmail.com 